\title{
Exploring how inter-organizational relational benefits affect information sharing in supply chains
}

\author{
Jao-Hong Cheng • Shu-Wei Chen · Fang-Yuan Chen
}

Published online: 19 June 2013

(c) The Author(s) 2013. This article is published with open access at Springerlink.com

\begin{abstract}
This research explores how inter-organizational relationship interacts with factors affecting the development and implementation of information sharing. On the basis of the resource-based view and relational risk perspective, we developed a model which comprises three research hypotheses with three constructs, including relational benefits, relational risk, and information sharing. The constructs are measured by well-supported measures in the literature. Structural equation modeling was used to analyze survey data collected from 528 manufacturing firms that were among the top 1,000 Taiwanese manufacturing firms of 2011 listed by Business Weekly. The results of the empirical study suggest that relational benefits are critical in ensuring information sharing and mitigate relational risk in the process. The findings of the study provide useful insights into how supply chain members can reinforce their relational benefits and mitigate probable risks so as to improve their collaborative behaviors and in turn enhance information sharing for the supply chain as a whole.
\end{abstract}

Keywords Relational benefit - Relational risk · Inter-organizational relationship · Information sharing

J.-H. Cheng $(\varangle) \cdot$ S.-W. Chen

Department of Information Management, National Yunlin University of Science and Technology, 123 University Road, Section 3, Douliou, Yunlin 64002, Taiwan

e-mail: jhcheng@yuntech.edu.tw

F.-Y. Chen

Department of Transportation Technology and Management, Feng Chia University, 100 Wenhwa Road, Seatwen,

Taichung 40724, Taiwan

\section{Introduction}

Information sharing has increasingly become an important issue for the supply chains. By making greater information available and sharing it among supply chain members such as suppliers or subcontractors, a manufacturing firm can make better decisions on ordering, production planning, and capacity allocation so that the supply chain dynamics can be optimized [1]. Information sharing plays a key role in a supply chain since it can help firms to achieve specific objectives and benefits in terms of reductions in total costs and inventories to maximize profits [2,3] and enhance supply chain performance [4]. Because it enhances the competitive advantage of the supply chain as a whole, inter-organizational information sharing in a supply chain has thus become a common practice [5-7].

To achieve the advantages of information sharing, it is of strategic importance for the firms to understand those factors relating to inter-organizational relationships that affect the members' intention to exchange information. Existing research has focused on modeling all the factors under investigation as precursors or independent variables that directly affect the behaviors of inter-organizational information sharing [6-8]. Research on inter-organizational information sharing, have examined uncertainty, facilitators, trust, commitment, and shared vision, among other factors [6]. Little has examined the inter-relationship between relational governance and risk management that affect information sharing and these relationships, despite being an important issue in inter-organizational research [9, 10]. It is generally believed that the information sharing is greater when parties have a good relationship [11]. As such, both partners in a relationship begin to value the relationships and the probability of relational risk behaviors will diminish accordingly. 
Relational governance and risk management are major perspectives which concern the maintenance of the relationship between supply chain members and mitigate the probability of relational risk behaviors in supply chains [9, 10]. Creating superior governance value and managing probable relational risk are fundamental to a firm's long-term survival and success in supply chains. Because partners that deliver superior benefits will be highly valued, a firm will commit to developing and maintaining relationships with partners [12-14]. It implies that firms are confronted with a relational risk when they develop inter-organizational relationships $[15,16]$. Thus, value-based relationships become part of relational governance, which involves the evaluation of the risk and benefits that a company incurs through the relational exchange. Resource-based view concentrates on the specific relational resources, which can be measured based on the benefits gained through relationships, among other factors. Consequently, this study draws on the theories of relational view (such as resource-based view), supplemented by the relational risk, to examine what value-based relationships can improve information sharing in supply chains.

To address this issue in supply chains, this study examines how inter-organizational relational benefits affect information sharing in supply chains. Relational benefits are used to measure benefits derived from relationships. Then, we look into how relational risk mediates the influence of inter-organizational relational benefits on interorganizational information sharing. To verify this research model, an empirical study of Taiwan's top 1,000 manufacturing firms and their supply chain suppliers and subcontractors was conducted.

In subsequent sections, we first give an overview of inter-organizational relationship and information sharing in supply chains. Next we discuss the factors affecting interorganizational information sharing and present the research model with three hypotheses. We then describe the survey instrument developed and the data collected from manufacturing firms in Taiwan, followed by testing the model using structural equation modeling. Finally, we discuss the results, their theoretical and practical implications, and suggestions for future research.

\section{Relational governance and risk management in inter-organizational information sharing}

Inter-organizational information sharing can enhance each firm's information base and competitiveness as information is a source of competitive advantage [5, 17]. Information sharing in the supply chain involves activities relevant to transferring or disseminating valuable information from manufacturing firms to their partners, with a view to developing value-added capabilities for effective problemsolving. By taking greater information available and sharing it with partners, a manufacturing firm can enhance information flow, respond quickly to changing customer needs, and improve the efficiency and effectiveness of the supply chain [6, 18]. To achieve the benefits of interorganizational information sharing, it is essential for all the parties involved to value the relationships and control the probability of relational risk behaviors more appropriately.

Relational governance and risk management are key determinant of competitive advantage, which are built and enhanced to achieve corporate goals. Prior research almost unanimously supports the positive influence of inter-organizational relationships on a firm's performance [12, 19, 20]. Nevertheless, some scholars suggested some possible negative influences of strong embedded ties on business success [21, 22]. Anderson and Jap [21] proposed that close interfirm relationships "provide an opportunity for covert activities designed to systematically cheat a partner". Selnes and Sallis [22] argued that a dark side of relationship can have a negative interaction between trust and knowledge exchange behavior on relationship performance. Relational governance is the most important instrument applied by the partners to manage relational risk [9, 10]. Managing relational risk requires appropriate relational governance for adaptable control and collaboration simultaneously in a dynamic environment. Relational governance has been shown to solve exchange problems and enhance performance [20]. Several prevailing theories have recommended relational governance for managing supply chain relationships and relational risk behaviors. Resource-based view and relational risk are relative to theories of relational view. Resource-based view emphasizes the collaboration for generating value from resourcebased and the others concentrate on relational risk behaviors and opportunistic behaviors from the social environment. The establishment of a high level of information sharing through close relationships among supply chain partners enhances the competitive advantage of the supply chain as a whole [23].

Resource-based view is a key theoretical perspective for analyzing specific relational resources in supply chains. Relational benefits as an important element of relational resources are consistent with the value-based perspective [24] that emphasizes the collaboration for generating value from relational resource. In service relationships, the relational benefits provided by the company affect the customer's willingness to build and maintain long-term and positive relationships with the company [25]. This in turn will create customer loyalty, improved sales levels and higher profit margins. On the whole, the mutual interests can influence the willingness to cooperate and connect and the inclination to maintain interrelationships. As the 
cooperative relationship leads to favorable effects cooperation will be adopted as the norm.

In agreement with the organizational behavior literatures, not all relationships result in mutual benefits [26]. Previous studies have disclosed part of the dark side of close interfirm relationships where partners have the incentive to contort the cooperation due to conflicts of interest between firms $[15,16]$. Inter-organizational relationships are characterized by inherent instability arising from uncertainty with respect to a partner's future behavior and the lack of a higher control to force compliance. Consequently, when firms develop inter-organizational relationships, they are confronted with relational risks [15, 16, 27], such as opportunistic behaviors, dysfunctional conflicts, non-learning risks and loss of competences. The concept of relational risk includes the probability and effect that partners do not cooperate in a desired manner [28]. According to this perspective, the partners in a relationship will behave opportunistically to endanger the cooperation.

To address this issue of inter-organizational information sharing in supply chains, this study examines how interorganizational relational benefits through relational risk affect information sharing in supply chains. Firms tend to band together if they perceive cooperation with each other will create value to the interfirm relationship. The value created by successful supply chain collaboration benefits all parties [29]. Accordingly, supply chain partners in a collaborative relationship begin to reinforce intention to connect in an attempt to achieve information sharing behavior and will not behave opportunistically because they do not want to endanger the relationship [30]. The constructs and hypotheses of the research model are discussed in the section that follows.

\section{The research model}

Figure 1 shows the new research model with the factors. It begins with inter-organizational relational benefits and then proceeds on to the mediating variables which also affect information sharing. Three hypotheses were tested with respect to this model. Each hypothesis is indicated by the letter $\mathrm{H}$ and a number. The arrows indicate the hypothesized relationships, and the plus and minus signs indicate positive and negative relationships respectively.

\subsection{Relational benefits}

Prior research has shown that relational benefit is an antecedent to building a long-term relationship [25, 31]. Relational benefits refer to the benefits that customers receive from long-term relationships above and beyond the core product or service performance [25]. In a supply chain, partners in relational exchanges cooperate to enhance more overall inter-organizational performance. The partner will choose to cooperate with the firm that provides it with greater benefits. Generally, perception of benefit depends on several dimensions pertaining to productivity, effectiveness, product profitability, customer satisfaction, and market share performance [12, 32]. If supply chain partners perceive relational benefits as a part of a long-term relationship, then this would subsequently increase the interorganizational knowledge or information sharing [33]. Such attitudes will be further reflected as a positive influence on information sharing behavior. It is thus hypothesized that:

H1 Relational benefits are positively related to information sharing

Relationship benefits are one of the critical relationship commitment decision factors [12]. In general, inter-organizational benefits lead directly to cooperative behaviors for relational exchange success and involve little risks. While the relational benefits are weak, the partner will not abide by their commitment out of their own interests and this will lead to a possibly risky situation. It is thus hypothesized that:

H2 Relational benefits are negatively related to relational risk

\subsection{Relational risk}

In strategic alliances, relational risk is defined as the probability and consequences of not having satisfactory cooperation [34] or as the probability and consequence of experiencing opportunistic behavior by the partner [27, 35]. The potential competitive relationship in supply chains

Fig. 1 The research model

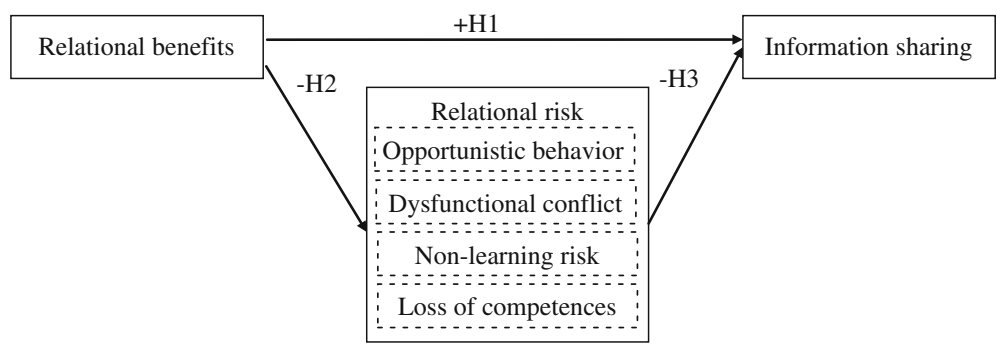


can lead to relational risk behaviors by a partner. In this study, we adopt widely recognized factors related to partner's behavior and dependence in a supply chain, including opportunistic behavior, dysfunctional conflict, non-learning risk, and loss of competences, to determine relational risk. These will act as impediments to inter-organizational information sharing. The concept of opportunistic behavior is defined as "self-interest seeking with guile" [36]. Opportunistic behaviors involve deceit-oriented violation of implicit or explicit promises about one's appropriate or required role behavior [37]. The opportunistic partners may overthrow alliance goals if it becomes necessary to achieve their own goals [38]. Dysfunctional conflicts arise because firms have private benefits that are not necessarily congruent with those of their partners. Inter-organizational relationship involves various possible risk behaviors where partners do not cooperate in a desired manner [28].

It has an opportunistic side because relationship partners place an emphasis on needs when influencing others [39] and on information gatekeeping [40]. Furthermore, some firms may have hidden agendas in the alliance such as secretly learning valuable know-how from the relationship partner that may subsequently create serious problems in cooperative interactions. Some relationship partners may have deployment strict policies or shielding mechanisms to protect core competences. All this suggests the possibility of low commitment to the cause of producing common benefits. In summary, firms must protect themselves against key knowledge appropriation by partners' relational risk behaviors [41], thus impeding knowledge or information sharing between firms [42]. It is thus hypothesized that:

H3 Relational risk is negatively related to information sharing

\section{Research method}

To develop the survey instrument, a pool of items was identified from the literature for measuring the constructs of the research model. Data from a survey sample were collected to assess the instrument's validity and reliability, and to test the hypothesized relationships of the research model.

\subsection{Content validity}

All measures of the survey instrument were developed from supply chain literature. To measure relational benefits, we developed three items based on two studies [12, 43]. The twelve-item relational risk scale was based on the work of Morgan and Hunt [12], Delerue [27], Williamson [36], Menon et al. [44], Simonin [45], and Morris and
Cadogan [46]. Finally, the three information sharing items were adapted from $\mathrm{Li}$ and Lin [6]. The English version was developed first, then translated into Chinese, and then back-translated into English. When the back-translated English version was checked against the original English version, some questions were reworded to improve the accuracy of the translation. The expressions of the items were adjusted, where appropriate, to the context of supply chains, as shown in Table 1. The items were to be measured on a seven-point Likert scale, ranging from 'Strongly disagree' (1) to 'Strongly agree' (7).

\subsection{Pre-test and pilot-test}

A pre-test was performed with three expert academics and four Ph.D. students on a questionnaire consisting of 18 items of the survey instrument for improvement in its content and appearance. Several large manufacturing firms were contacted to help with the pilot-test of the instrument. This study sought to choose respondents who were expected to have the best knowledge about the operation and management of the inter-organizational relationships between their manufacturing firm and its suppliers or subcontractors. Based on literature [47, 48] and recommendations from practitioners who were professionally knowledgeable about the operation and management of the inter-organizational relationships between their manufacturing firm and its suppliers or subcontractors, it was decided that function managers who are in the senior management team and involved in maintaining and developing inter-organizational relationships with suppliers or subcontractors of the firm be chosen as respondents for the current study. A survey packet including a cover letter explaining the research objectives, the questionnaire, and a stamped, return-addressed envelope, was distributed to the function managers of each participating firm. The respondents were asked to complete the questionnaire and provide comments on the wording, understandability and clarity of the items; in addition, the overall appearance and content of the instrument were also taken into account in the pilottest.

Only minor changes were suggested and no statements were removed. After making those adjustments and a review of the questionnaire again by two other expert academics, the instrument was ready to be sent to a large sample for the purpose of data collection for the verification of our research model. Table 1 shows the 18 items together with the corresponding constructs to be measured.

\subsection{Data collection}

The data were collected from organizations that were among the top 1,000 Taiwanese manufacturing firms of 
Table 1 Measurement items

\begin{tabular}{|c|c|c|}
\hline \multicolumn{2}{|c|}{ Construct } & \multirow[t]{2}{*}{ Source } \\
\hline Relatio & benefits & \\
\hline RB1 & Averagely speaking, the expected product profits of you and your partner in your cooperation is good & {$[12]$} \\
\hline RB2 & Averagely speaking, the expected product performance of you and your partner in your cooperation is good & [12] \\
\hline RB3 & Averagely speaking, the expected satisfaction of you and your partner in your cooperation is good & [43] \\
\hline \multicolumn{3}{|c|}{ Relational risk } \\
\hline RR1 & To accomplish his own goals, sometimes your partner alters the facts slightly & {$[12,36]$} \\
\hline RR2 & To accomplish his own goals, sometimes your partner promises to do things without actually doing them later & {$[12,36]$} \\
\hline RR3 & Your partner breaches formal or informal agreements for his benefit & [46] \\
\hline RR4 & You will interfere with the decision making process in the cooperation & {$[44,46]$} \\
\hline RR5 & You will overstate your needs to try to influence your partner & {$[44,46]$} \\
\hline RR6 & You will overstate some information or facts to try to influence your partner & {$[44,46]$} \\
\hline RR7 & Your partner has procedures to restrict the sharing of relevant information concerning its technology/know-how & {$[27,45]$} \\
\hline RR8 & Your partner has routines to restrict the sharing of relevant information concerning its technology/know-how & {$[27,45]$} \\
\hline RR9 & Your partner has policies to restrict the sharing of relevant information concerning its technology/know-how & {$[27,45]$} \\
\hline RR10 & Our company has been able to protect its core capabilities from our partner & [27] \\
\hline RR11 & Our company has been able to protect its core skills from our partner & [27] \\
\hline RR12 & Our company has been successful in protecting its crown jewels form being appropriated by our partner & [27] \\
\hline \multicolumn{3}{|c|}{ Information sharing } \\
\hline IS1 & Our partners share proprietary information with us & [6] \\
\hline IS2 & We provide information to our partner that might help our partner & [6] \\
\hline IS3 & We provide information to our partner frequently and informally, and not only according to the specific agreement & [6] \\
\hline
\end{tabular}

2011 listed by Business Weekly (Taiwan's leading business magazine). The result of this survey was 528 effective responses with the total response rate of $52.8 \%$. A Chi square analysis of the industry distribution of the respondents showed no difference from the industry distribution of all the firms used in the survey. The respondents were then further divided into two groups, including respondents and non-respondents. The comparison on industry type, total sales revenue, and years of establishment of the two groups also showed no significant differences based on the independent sample Chi square test $(p=0.542,0.602$ and 0.711 , respectively). This suggested no non-response bias in the returned questionnaires. Table 2 shows the demographic and characteristic profiles of participating firms.

Additionally, the 528 respondents were function managers or other managers in the senior management team as in the case of the general manager, vice president, or CEO. To check for the potential bias of a single informant, the consistency between the data collected from function managers and other senior managers was verified. Consistent with past research [49], inter-rater reliabilities (IRR) were calculated to show the agreement level between function managers and other senior managers. The average estimates of IRR were 0.912 for relational benefit, 0.901 for relational risk, and 0.912 for information sharing, respectively. All estimates exceeded the recommended cut-off value of 0.7 [50], indicating the response consistency between the two groups.

\section{Results}

Structural equation modeling (SEM) with LISREL 8.52 [51] was used to test and analyze the hypothesized relationships of the research model. SEM aims to examine the inter-related relationships between a set of posited constructs simultaneously; each construct is measured by one or more observed items (measures). SEM involves the analysis of two models: a measurement (or confirmatory factor analysis) model and a structural model [52]. The measurement model specifies the relationships between the observed measures and their underlying constructs, which are allowed to inter-correlate, and the structural model specifies the posited causal relationships among the constructs.

\subsection{Assessment of the measurement model}

Prior to the analysis, we performed exploratory factor analysis using principal axis factoring to ascertain whether our items loaded onto a common latent factor. With the measures and their underlying constructs shown in Table 1, the measurement model specified for the research model was found to be able to ascertain the extent to which the observed measures (surveyed items) actually measure their corresponding construct. The 18 items of the survey instrument were first analyzed to assess their dimensionality and measurement properties. An assessment of the 
Table 2 Profiles of participating manufacturing firms

\begin{tabular}{|c|c|c|c|c|c|}
\hline Demographic profile & $\begin{array}{l}\text { Number } \\
\text { of firms }\end{array}$ & Percentage & Chi square & $\mathrm{df}$ & $p$ value \\
\hline \multicolumn{6}{|l|}{ Industry type } \\
\hline Agricultural/food/beverage & 19 & 3.6 & 12.627 & 12 & 0.513 \\
\hline Textiles/fiber & 22 & 4.2 & & & \\
\hline Leather/footwear & 3 & 0.6 & & & \\
\hline Timber/bamboo/rattan & 3 & 0.6 & & & \\
\hline Printing and related support activities & 12 & 2.3 & & & \\
\hline Chemical/plastics & 80 & 15.2 & & & \\
\hline Non-metallic mineral products & 15 & 2.8 & & & \\
\hline Basic metal industries & 59 & 11.2 & & & \\
\hline $\begin{array}{l}\text { Electrical machinery/Machinery } \\
\text { and equipment }\end{array}$ & 55 & 10.4 & & & \\
\hline Electronics/communication & 167 & 31.6 & & & \\
\hline Transport equipment & 34 & 6.4 & & & \\
\hline Electronic parts and components & 39 & 7.4 & & & \\
\hline Others & 20 & 3.8 & & & \\
\hline \multicolumn{6}{|l|}{ Total sales revenue (New Taiwan \$) } \\
\hline Below $\$ 2$ billion & 68 & 12.9 & 6.551 & 7 & 0.424 \\
\hline$\$ 2.1$ billion to below $\$ 3$ billion & 72 & 13.6 & & & \\
\hline$\$ 3.1$ billion to below $\$ 4$ billion & 86 & 16.3 & & & \\
\hline$\$ 4.1$ billion to below $\$ 5$ billion & 90 & 17.0 & & & \\
\hline$\$ 5.1$ billion to below $\$ 10$ billion & 96 & 18.2 & & & \\
\hline$\$ 10.1$ billion to below $\$ 20$ billion & 65 & 12.3 & & & \\
\hline$\$ 20.1$ billion to below $\$ 50$ billion & 39 & 7.4 & & & \\
\hline$\$ 50.1$ billion and above & 12 & 2.3 & & & \\
\hline \multicolumn{6}{|l|}{ Years of establishment } \\
\hline Less than 5 years & 6 & 1.1 & 7.924 & 6 & 0.644 \\
\hline $6-10$ years & 50 & 9.5 & & & \\
\hline $11-15$ years & 73 & 13.8 & & & \\
\hline $16-20$ years & 62 & 11.7 & & & \\
\hline $21-25$ years & 87 & 16.5 & & & \\
\hline 26-30 years & 71 & 13.4 & & & \\
\hline Over 31 years & 179 & 33.9 & & & \\
\hline \multicolumn{6}{|l|}{ Position of respondent } \\
\hline Top managers & 315 & 59.7 & 2.01 & 1 & 0.692 \\
\hline Function managers & 213 & 40.3 & & & \\
\hline
\end{tabular}

eigenvalues suggested a three-factor solution, including relational benefits, relational risk, and information sharing. Besides this, all items loaded significantly and substantially on their underlying constructs, thus providing evidence of convergent validity. With a confirmatory factor analysis, all items performed well and were thus retained in the model.

The Chi square of the measurement model was significant $(\chi 2=225.706, \mathrm{df}=465, p<0.01)$, with the value of $\chi 2 /$ df smaller than 2 , indicating an ideal fit [53]. The large Chi square value was not surprising since the Chi square statistic has been shown to be directly related to sample size [51]. To assess the overall model fit without being affected by the sample size, alternative stand-lone fit indices less sensitive to sample size were used. These indices included the goodness of fit index (GFI), the adjusted goodness of fit index (AGFI), the comparative fit index (CFI), and the root mean square error of approximation (RMSEA) [51]. To have a good model fit, GFI should be close to 0.90, AGFI more than 0.80, CFI more than 0.9, RMSR less than 0.05, and RMSEA less than 0.10 [51]. An assessment of the measurement model suggests an acceptable model fit $(\mathrm{GFI}=0.922 ; \quad$ AGFI $=0.903$; $\mathrm{CFI}=0.959 ; \mathrm{NFI}=0.920 ;$ RMSEA $=0.046$ ).

To assess the reliability of the constructs, composite reliability (CR) was facilitated. All of the composite 
Table 3 Assessment results of the measurement model

\begin{tabular}{llllrlll}
\hline Construct & Items & $\begin{array}{l}\text { Standardized } \\
\text { loading }\end{array}$ & $\begin{array}{l}\text { Standardized } \\
\text { error }\end{array}$ & $t$ value & SMC & CR & AVE \\
\hline Relational benefits & RB1 & $0.749 * *$ & 0.128 & 9.261 & 0.541 & 0.918 & 0.790 \\
& RB2 & $0.779 * *$ & 0.139 & 8.484 & 0.868 & & \\
Relational risk & RB3 & $0.631 * *$ & 0.146 & 6.551 & 0.743 & & \\
& RR1 & $0.789 * *$ & 0.180 & 7.521 & 0.830 & 0.937 & 0.557 \\
& RR2 & $0.828 * *$ & 0.071 & 8.631 & 0.761 & & \\
& RR3 & $0.851 * *$ & 0.260 & 9.131 & 0.621 & & \\
& RR4 & $0.624 * *$ & 0.178 & 10.053 & 0.391 & & \\
& RR5 & $0.914 * *$ & 0.164 & 3.294 & 0.836 & & \\
& RR6 & $0.875 * *$ & 0.261 & 4.769 & 0.768 & & \\
& RR7 & $0.749 * *$ & 0.340 & 5.653 & 0.431 & & \\
& RR8 & $0.818 * *$ & 0.549 & 3.770 & 0.319 & & \\
& RR9 & $0.711 * *$ & 0.941 & 10.193 & 0.491 & & \\
& RR10 & $0.668 * *$ & 0.869 & 9.181 & 0.551 & & \\
& RR11 & $0.742 * *$ & 0.979 & 5.366 & 0.450 & & \\
& RR12 & $0.698 * *$ & 0.968 & 6.502 & 0.509 & & \\
Information sharing & IS1 & $0.882 * *$ & 0.258 & 4.981 & 0.781 & 0.922 & 0.801 \\
& IS2 & $0.747 * *$ & 0.036 & 8.551 & 0.570 & & \\
& IS3 & $0.625 * *$ & 0.134 & 10.073 & 0.502 & &
\end{tabular}

** Significance at $p<0.05$

\subsection{Common method bias}

reliability values, ranging from a low of 0.918 to a high of 0.937 , exceeded the recommended cut-off value of 0.80 [51]. A variable's squared multiple correlation (SMC) is the proportion of its variance that is accounted for by its predictors. The average variance extracted (AVE) was greater than 0.5 in all cases, meaning that the variance accounted for by each of the constructs was greater than the variance accounted for by measurement error [51]. In addition, an assessment of discriminant validity between the constructs supported the model fit. Table 3 summarizes the assessment results of the measurement model.

\subsection{Assessment of the structural model}

Table 4 refers to the inter-correlations between three constructs of the structural model, which supports the positive and negative relationships of the research model in Fig. 1. The overall fit of the structural model is acceptable, since all measures of fit reach an acceptable level $(\chi 2=230.092$, $\mathrm{df}=466, p<0.01 ; \mathrm{GFI}=0.909 ; \mathrm{AGFI}=0.900 ; \mathrm{CFI}=$ 0.931; NFI $=0.914$; $\mathrm{RMSEA}=0.048$ ).

Table 4 Correlation matrix of constructs

\begin{tabular}{lrrr}
\hline Construct & (1) & (2) & (3) \\
\hline (1) Information sharing & 1.000 & & \\
(2) Relational benefits & 0.325 & 1.000 & \\
(3) Relational risk & -0.496 & -0.556 & 1.000 \\
\hline
\end{tabular}

Following the suggestion of [54], Harmon's one-factor test was run to ensure that common method variance did not account for our findings. Unrotated principal components analysis revealed three factors with eigenvalues greater than 1 , which accounted for $61.1 \%$ of the total variance. The first factor did not account for the majority of the variance $(21.7 \%)$. As no single factor emerged that accounted for most of the variance, common method bias does not appear to be a problem in the study.

\subsection{Hypotheses testing}

In SEM analysis, the relationships among independent and dependent variables were assessed simultaneously via covariance analysis. Maximum likelihood (ML) estimation was facilitated to estimate model parameters with the covariance matrix as data input. The ML estimation method has been described as being well suited to theory testing and development [52].

Figure 2 shows the structural model with the coefficients for each path (hypothesized relationship), where all hypothesized relationships are supported. Relational benefits are significantly associated with information sharing (H1: $\gamma=0.248, \mathrm{t}=2.312, p<0.05$ ). Relational benefits has a negative impact on relational risk $(\mathrm{H} 2: \gamma=-0.215$, $\mathrm{t}=-3.832, p<0.01)$. Relational risk has a negative impact on information sharing $(\mathrm{H} 3: \gamma=-0.140, \mathrm{t}=$ $-2.816, p<0.01)$. Overall, the model explains $31.6 \%$ of 
Fig. 2 The structural model

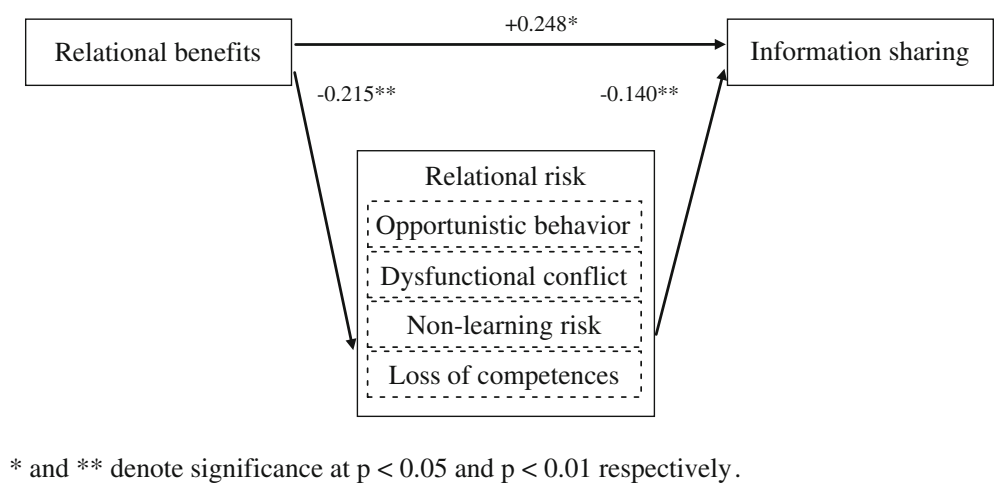

the variance in relational risk and $59.5 \%$ in information sharing.

\subsection{Comparison with alternative models}

This paper followed the procedure suggested by [55] and evaluated three models shown in Table 5. The first was the proposed model: it allowed the partial mediation of relational risk while the second allowed fully mediation of relational risk. The third contained relational benefits and relational risk, and their direct impact on information sharing without any mediating variables.

Model 1 proposed a partial mediated model for the effect of relational risk on information sharing, which was supported by our data. This model represents one of several possible ways in which the relationships between the constructs could be configured. Alternative models could also provide plausible predictions and explanations about the influences of relational risk on information sharing.

Table 5 Alternative models

\begin{tabular}{|c|c|c|c|}
\hline Attribute & $\begin{array}{l}\text { Model 1: partially } \\
\text { mediated (proposed } \\
\text { model) }\end{array}$ & $\begin{array}{l}\text { Model 2: fully } \\
\text { mediated }\end{array}$ & $\begin{array}{l}\text { Model 3: all } \\
\text { direct effects }\end{array}$ \\
\hline \multicolumn{4}{|c|}{ Standardized path estimates } \\
\hline $\mathrm{RB} \rightarrow \mathrm{IS}$ & $0.248 *$ & - & $0.284 * *$ \\
\hline $\mathrm{RB} \rightarrow \mathrm{RR}$ & $-0.215 * *$ & $-0.226 * *$ & - \\
\hline $\mathrm{RR} \rightarrow \mathrm{IS}$ & $-0.140 * *$ & $-0.140 * *$ & $-0.141 * *$ \\
\hline $\mathrm{R}^{2}(\mathrm{RR})$ & $31.6 \%$ & - & - \\
\hline $\mathrm{R}^{2}(\mathrm{IS})$ & $59.5 \%$ & $49.2 \%$ & $34.7 \%$ \\
\hline \multicolumn{4}{|c|}{ Model fit indices } \\
\hline$\chi 2(\mathrm{df})$ & $230.092(466)$ & $283.291(469)$ & $448.324(471)$ \\
\hline GFI & 0.909 & 0.899 & 0.831 \\
\hline AGFI & 0.900 & 0.891 & 0.825 \\
\hline CFI & 0.931 & 0.915 & 0.869 \\
\hline NFI & 0.914 & 0.906 & 0.856 \\
\hline RMSEA & 0.048 & 0.080 & 0.137 \\
\hline
\end{tabular}

*,** Significance at $p<0.05$ and $p<0.01$ respectively
Specifically, relational benefit could affect information sharing through the mediation of relational risk (i.e. Model 2 ). On the other hand, relational benefits and relational risk could have a direct impact on information sharing without any mediation (i.e. Model 3). To explore these possibilities, we compared Model 1 with two alternative models, Models 2 and 3, on the following criteria: (1) the same model fit indices used to assess the research model; (2) the explanatory power of the predictive variables on the outcome variables, as measured by the $\mathrm{R}^{2}$ of the outcome variables; (3) the percentage of the model's hypothesized parameters that are statistically significant. A comparison of the direct effect of relational benefits on information sharing between Models 1 and 3 revealed that the path coefficient of relational benefits dropped from 0.284 in Model $3(p<0.01)$ to 0.248 in Model $1(p<0.05)$ when the mediators were introduced into the model, revealing that relational risk partially mediated the influence of information sharing. The results satisfied the conditions suggested by [55]. Model 1 was better than Models 2 and 3 on all indices. With regard to the explanatory power, Model 2 explained a large percentage of variance $(49.2 \%)$. Model 3 explained only $34.7 \%$ of the variance of information sharing. The results suggested that the partially mediated model was relatively better. Since the model fit indices were lower in Model 2 and Model 3, we conclude that Model 1 would be a better representation of the relationships among the constructs due to its good model fit.

\subsection{Multi-group analysis}

According to the returned questionnaires, the main area in which manufacturers and subcontractors (or suppliers) collaborate is technology transfer to develop new technologies and products ( $49.05 \%$ of the collaboration items), which indicates that almost half of the collaboration is related to R\&D. The 528 usable responses are divided into two groups. The group 1's collaboration is related to R\&D; on the other hand, the group 2 's collaboration isn't related to R\&D. For examining the differences between the parameters of the two 
groups, the statistical comparison is made following the multi-group procedure suggested by [51]. With this procedure individual paths are separately examined across groups and it is tested whether the estimated coefficients for each group are equal using a Chi square difference test. The path coefficients of both groups were separately analyzed using a multiple group analysis, assuring that the model's goodness of fit is similar for both. For the R\&D collaboration group, the fit indices were acceptable $\left(\chi^{2} / \mathrm{df}=0.47\right.$, GFI $=0.909$; AGFI $=0.903 ;$ CFI $=0.933 ; \quad \mathrm{NFI}=0.915 ;$ RMSEA $=$ $0.045)$. For another group, the fit indices were also acceptable $\left(\chi^{2} / \mathrm{df}=0.56, \mathrm{GFI}=0.906 ; \mathrm{AGFI}=0.879 ; \mathrm{CFI}=0.928\right.$; NFI $=0.909 ;$ RMSEA $=0.051)$. The estimation results show that the differences between the parameters of the two groups are significant. The findings reveal that relational benefits has a significant positive impact on inter-organizational information sharing in the group $1(\gamma=0.232$, $\mathrm{t}=2.831, p<0.01)$, but less significant in the group 2 $(\gamma=0.234, \mathrm{t}=1.812, p<0.05)$. Relational benefits is significantly associated with relational risk in the group $1(\gamma=$ $-0.267, \mathrm{t}=-5.011, p<0.001)$, but less significant in the group $2(\gamma=-0.165, \mathrm{t}=-2.677, p<0.01)$. Relational risk has a less significantly negative impact on information sharing $(\gamma=-0.109, \mathrm{t}=-2.314, p<0.05)$ in the group 1 , while significant is found in the group $2(\gamma=-0.170$, $\mathrm{t}=-3.299, p<0.01)$.

\section{Discussion}

It is not surprising that relational benefits display a significantly positive effect on inter-organizational information sharing in Taiwan's supply chains. This is consistent with the value-based perspective [24]. According to this perspective, creating superior customer value is fundamental to a firm's long-term survival and success [13]. Firms tend to band together while they perceive cooperation among members of the Taiwan's supply chain will bring benefits that add value to the interfirm relationship. The critical role relationship benefits play in interfirm collaboration is supported by Ulaga and Eggert's findings that relationship benefits take on more weight than relational costs in the formation of customer value in business markets [24].

Conforming to the hypothesis, relational benefits show evidence of a negative relationship with relational risk. This finding is in line with previous research on the subject. This may reflect that relational benefits of the supply chain parties are so considerable that relational risk among them is tolerated and conceived of as acceptable for achieving better information sharing. Therefore, it is essential that the firms are able to control these risks. This finding suggests that a good practice in forming an inter-organizational relationship in supply chains is to reinforce their relational benefits and thus mitigate probable relational risks. Traditionally, firms have tended to focus on the applications of IT on supply chain management; they have paid less attention on the development of inter-organizational relationships [6]. Our results instead demonstrate that the establishment of good inter-organizational relationships is a must for supply chain members.

Relational risk is found to have a negative impact on inter-organizational information sharing. This finding is noteworthy. It is well documented in the literature that there may be a 'dark side' in the long-term relationship [27, 56]. Some possible explanations regarding these relational dynamics include: parties in a long-term relationship may have the probability to act opportunistically [56], have lost their objectivity, or have become too similar in thinking and therefore have less value to add. These phenomenon suggest that relational risk may well coexist with benefits at some points of time in the progressive development of supply chain relationships. This should put managers on alert that they must watch and understand what their partners really value at any stage of a relationship and deliver what are expected before the 'dark side' emerges. To the extent that you can offer superior benefits to the partner, the less likely relational risk behaviors would occur.

\subsection{Theoretical implications}

With the development of the new research model, the theoretical contributions of this paper to the literature are described as follows. To the best of our knowledge, the current study appears to be the first attempt to address the important issue of information sharing improvement in the context of supply chains. First, the results of this study contribute to the development of literature relating to interorganizational information sharing in supply chain. Specifically, although risk is an important opinion in the literature, noteworthy gaps remain in understanding its impact on inter-organizational information sharing [6-8]. We attempted to fill the gaps by identifying relational risk behaviors and investigated how the proposed antecedent affects inter-organizational information sharing. Therefore, this study makes a theoretical contribution in incorporating relational benefits with relational risk and inter-organizational information sharing for investigating the inter-organizational relationships between supply chain members. The theoretical framework established in this work can be applied to other forms of inter-organizational relationships involving information sharing.

Secondly, further the multi-group analysis of relational governance and risk management is a direct extension of the literature. According to our findings, relational benefits 
is significantly and positively associated with inter-organizational information sharing in the R\&D collaboration group (group 1), but less significant in the without $R \& D$ collaboration group (group 2). Moreover, Relational risk has a less significantly negative impact on information sharing in the $R \& D$ collaboration group (group 1), while significant is found in the without $R \& D$ collaboration group (group 2). These activities of $R \& D$ collaboration are related to $R \& D$ functions that require substantial amounts of human resources, machines, time and a handsome sum of money to produce greater profits and the positive quality of cooperation [47]. In the R\&D collaboration group (group 1), there would be no cut-and-run because the party perceives that only through continuity of collaboration can be the net-gainer and gains be achieved in the future. Thus, partners should ensure that there are stronger relational benefits within organizations so that relational risk behaviors do not damage the relationship or the future information sharing.

\subsection{Managerial and practical implications}

The result indicates that strengthening the business relationships leads to achieve company goals and create competitive advantages, inter-organizational information sharing is increasingly popular $[6,11]$.This study provides useful insights for managers in developing inter-organizational information sharing. The findings of this study on the effects of relational benefits and relational risk, not only are in line with prior research, but also reveal how information sharing is significantly affected by relational benefits through other mediating variables such as relational risk. The most important implication for managerial and practical insights is that developing positive and effective collaborative relationships with business partners are the key to enhancing inter-organizational information sharing in supply chains. Therein, relevant parties can develop collaborative relationships by focusing on activities that would reinforce relational benefits and avoid activities that would increase the probability of relational risk behaviors. The inter-organizational information sharing can be achieved efficiently by enhancing the relational views of relational governance and managing the relational risk behaviors.

\section{Conclusions}

It is of strategic importance for a firm to understand the factors influencing the information sharing behavior in an inter-organizational relationship in supply chains. The concept of our research proved to be an insightful approach for exploring issues related to relational governance and risk management in supply chains. The contributions of the paper to the literature are described as follows. First, this paper extends current research by highlighting both the positive and negative side of inter-organizational relationships on information sharing. This study contributes to a better understanding of how relational benefits and relational risk influence information sharing, a key determinant of the performance of a supply chain partnership. Second, this study provided insights into how the positive effect of relational benefits reinforces collaboration in order to achieve the information sharing. Third, relational risk is found to be negatively associated with inter-organizational information sharing. Especially, how the relational views of relational governance (such as relational benefits) restrain encroachment, which is not dealt with in previous studies (e.g., [11]). The findings of the study provide some practical insights into how supply chain members should reinforce their relational benefits so as to improve their value-based relationships and manage relational risk, in order to enhance inter-organizational information sharing for the supply chain as a whole.

This study suffers from some limitations relating to data collection and the interpretation of results. First, the findings reflect the setting of Taiwan's supply chains only. To address these inherent limitations, future research on crossindustrial studies on various forms of supply chains would be worth conducting to examine industrial differences in the development of inter-organizational relationships. Second, the subjects were manufacturing firms in Taiwan. However, differences in organizational culture exist in different sectors and different parts of the world. Finally, for reasons of simplicity and focus, this study did not consider all variables. Further research may also explore whether other constructs, such as relational governance mechanisms [57, 58], will affect inter-organizational relationships among relational benefits, relational risk and information sharing.

Acknowledgments This research was supported by the National Science Council of Taiwan, ROC, under Contract NSC 99-2410-H224-010-MY3.

Open Access This article is distributed under the terms of the Creative Commons Attribution License which permits any use, distribution, and reproduction in any medium, provided the original author(s) and the source are credited.

\section{References}

1. Huang GQ, Lau SK, Mak KL (2003) The impacts of sharing production information on supply chain dynamics: a review of the literature. Int J Prod Res 41:1483-1517

2. Yu Z, Yan H, Cheng TCE (2001) Benefits of information sharing with supply chain partnerships. Ind Manag Data Syst 101(3): $114-121$ 
3. Barua A, Ravindran S, Whinston AB (2007) Enabling information sharing within organizations. Inf Technol Manag 8(1):31-45

4. Liu Z, Wang G, Liu P (2011) Information sharing among members of the supply chain from the perspective of game. Adv Inf Sci Serv Sci 3(2):152-159

5. Drucker PF (1992) The new society of organizations. Harv Bus Rev 70:95-105

6. Li S, Lin B (2006) Accessing information sharing and information quality in supply chain management. Decis Support Syst 42(3):1641-1656

7. Shin SK, Ishman M, Sanders GL (2007) An empirical investigation of socio-cultural factors of information sharing in China. Inf Manag 44:165-174

8. Patnayakuni R, Rai A, Seth N (2006) Relational antecedents of information flow integration for supply chain coordination. J Manag Inf 23:13-19

9. Lee RP, Johnson JL (2010) Managing multiple facets of risk in new product alliances. Decis Sci 41(2):271-300

10. Szczepański R, Światowiec-Szczepańska J (2012) Risk management system in business relationships-Polish case studies. Ind Mark Manag 41:790-799

11. Du TC, Lai VS, Cheung W, Xiling C (2012) Willingness to share information in a supply chain: a partnership-data-process perspective. Inf Manag 49(2):89-98

12. Morgan RM, Hunt SD (1994) The commitment-trust theory of relationship marketing. J Market 58:20-38

13. Woodruff RB (1997) Customer value: the next source for competitive advantage. J Acad Mark Sci 25:139-144

14. Slater SF (1997) Developing a customer value-based theory of the firm. J Acad Mark Sci 25:162-168

15. Delerue H (2005) Relational risk perception and alliance management in French biotechnology SMEs. Eur Bus Rev 17(6):532-546

16. Ratnasingam P (2007) A risk-control framework for e-marketplace participation: the findings of seven cases. Inf Manag Comput Secur 15:149-166

17. Mentzer JT, Min S, Zacharia ZG (2000) The nature of interfirm partnering in supply chain management. J Retail 76:549-568

18. Xu K, Dong Y, Evers PT (2001) Towards better coordination of the supply chain. Transp Res Part E 37(1):35-54

19. Uddin MN, Islam N and Quaddus M (2011) Supply chain performance of the Australian beef industry. Western Australia, http://www.agric.wa.gov.au/objtwr/imported_assets/content/amt/ supply_chain_formance_australian_beef_industry_pdf. Accessed 06 May 2012

20. Heide JB, John G (1988) The role of dependence balancing in safeguarding relationship-specific assets in conventional channels. J Market 52:20-35

21. Anderson E, Jap SD (2005) The dark side of close relationships. Sloan Manag Rev 46(3):74-82

22. Selnes F, Sallis J (2003) Promoting relationship learning. J Market 67(3):80-95

23. Holland CP (1995) Cooperative supply chain management: the impact of inter-organizational information systems. J Strateg Inf Syst 4:117-133

24. Ulaga W, Eggert A (2006) Value-based differentiation in business relationships: gaining and sustaining key supplier status. J Market 70:119-136

25. Gwinner KP, Gremler DD, Bitner MJ (1998) Relational benefits in services industries: the customer's perspective. J Acad Mark Sci 26:101-114

26. Svensson G (2001) Extending trust and mutual trust in business relationships towards a synchronised trust chain in marketing channels. Manag Decis 39:431-440

27. Delerue H (2004) Relational risks perception in European biotechnology alliances: the effect of contextual factors. Eur Manag J 22(5):546-556
28. Das TK, Teng BS (2001) Relational risk and its personal correlates in strategic alliances. J Bus Psychol 15(3):449-465

29. Horvath L (2001) Collaboration: the key to value creation in supply chain management. Supply Chain Manag 6:205-207

30. William TR, Diana CR (2007) Compound relationships between firms. J Market 71(3):108-123

31. Patterson PG, Smith T (2001) Relationship benefits in service industries: a replication in a Southeast Asian context. J Serv Mark 15(6):425-443

32. Frazier GL, Spekman RE, O'Neal CR (1988) Just-in-time exchange relationships in industrial markets. J Market 52(4):52-67

33. Cheng JH (2011) Inter-organizational relationships and knowledge sharing in green supply chains-Moderating by relational benefits and guanxi. Transp Res Part E 47(6):837-849

34. Das TK, Teng BS (1996) Risk types and inter-firm alliance structures. J Manage Stud 33(6):827-843

35. Nooteboom B, Berger H, Noorderhaven N (1997) Effects of trust and governance on relational risk. Acad Manag J 40(2):308-338

36. Williamson OE (1975) Markets and hierarchies: analysis and antitrust implications. Free Press, New York

37. John G (1984) An empirical investigation of some antecedents of opportunism in a marketing channel. J Mark Res 21:278-289

38. Das TK (2004) Time-span and risk of partner opportunism in strategic alliances. J Manag Psychol 19(8):744-759

39. Barclay D (1991) Interdepartmental conflict in organizational buying: the impact of the organizational context. J Mark Res 28:145-159

40. Jaworski BJ, Kohli AK (1993) Market orientation: antecedents and consequences. J Market 57:53-70

41. Jordan J, Lowe J (2004) Protecting strategic knowledge: insights from collaborative agreements in the aerospace sector. Technol Anal Strateg Manag 16(2):241-259

42. Cheng JH, Yeh CH, Tu CW (2008) Trust and knowledge sharing in green supply chains. Suppl Chain Manag 13:283-295

43. Anderson JC, Narus JA (1990) A model of distributor firm and manufacturer firm working partnerships. J Market 54:42-58

44. Menon A, Bharadwaj SG, Howell R (1996) The quality and effectiveness of marketing strategy: effects of functional and dysfunctional conflict in intraorganizational relationships. J Acad Market Sci 24(4):299-313

45. Simonin BL (1999) Ambiguity and the process of knowledge transfer in strategic alliances. Strateg Manag J 20(7):595623

46. Morris BGA, Cadogan JW (2001) Partner symmetries, partner conflict and the quality of joint venture marketing strategy: an empirical investigation. J Market Manag 17:223-256

47. Cheng JH (2011) Inter-organizational relationships and information sharing in supply chains. Int J Inf Manag 31(4):374-384

48. Gosain S, Malhotra A, El Sawy OA (2004) Coordinating for flexibility in e-Business supply chains. J Manag Inf Syst 21(3): $7-45$

49. Weil P (1992) The relationship between investment in information technology and firm performance: a study of the value manufacturing sector. Inf Syst Res 3:307-333

50. Eby LT, Dobbins GH (1997) Collectivistic orientation in teams: an individual and group-level analysis. J Organ Behav 18:275-295

51. Joreskog KG, Sorbom D (1993) LISREL 8: Structural equation modeling with the SIMPLIS command language. Scientific Software International, Chicago

52. Anderson JC, Gerbing DW (1988) Structural equation modeling in practice: a review and recommended two-step approach. Psychol Bull 103:411-423

53. Bentler PM (1990) Comparative fit indexes in structural models. Psychol Bull 102:238-246

54. Podsakoff PM, Organ DM (1986) Self-reports in organizational research: problems and prospects. J Manag 12:531-544 
55. Baron RM, Kenny DA (1986) The moderator-mediator variable distinction in social psychological research: conceptual, strategic, and statistical considerations. J Pers Soc Psychol 51:1173-1182

56. Grayson K, Ambler T (1999) The dark side of long-term relationships in marketing services. J Mark Res 36(1):132-141

57. Ke W, Liu H, Wei KK, Gu J, Chen H (2009) How do mediated and non-mediated power affect electronic supply chain management system adoption? The mediating effects of trust and institutional pressures. Decis Support Syst 46:839-851

58. Liu H, Ke W, Wei KK, Gu J, Chen H (2010) The role of institutional pressures and organizational culture in the firm's intention to adopt internet-enabled supply chain management systems. J Oper Manag 28:372-384 